OPEN ACCESS

Edited by:

Markus H. Hoffmann, University of Erlangen Nuremberg, Germany

Reviewed by:

Sanja Arandjelovic, University of Virginia, United States Bo Sun,

Brigham and Women's Hospital and Harvard Medical School, United States

${ }^{*}$ Correspondence: Yongqing $L$ yqli@med.umich.edu

Specialty section: This article was submitted to Inflammation,

a section of the journal

Frontiers in Immunology

Received: 20 August 2021 Accepted: 20 October 2021 Published: 04 November 2021

Citation:

Wu Z, Li P, Tian Y, Ouyang W, Ho JW-Y, Alam HB and Li Y (2021)

Peptidylarginine Deiminase 2 in Host Immunity: Current Insights and Perspectives.

Front. Immunol. 12:761946. doi: 10.3389/fimmu.2021.761946

\section{Peptidylarginine Deiminase 2 in Host Immunity: Current Insights and Perspectives}

\author{
Zhenyu Wu ${ }^{1,2}$, Patrick $\mathrm{Li}^{1,3}$, Yuzi Tian ${ }^{1,4}$, Wenlu Ouyang ${ }^{1,2}$, Jessie Wai-Yan $\mathrm{Ho}^{5}$, \\ Hasan B. Alam ${ }^{5}$ and Yongqing $\mathrm{Li}^{{ }^{1 *}}$ \\ ${ }^{1}$ Department of Surgery, University of Michigan Hospital, Ann Arbor, MI, United States, ${ }^{2}$ Department of Infectious Diseases, \\ Xiangya $2^{\text {nd }}$ Hospital, Central South University, Changsha, China, ${ }^{3}$ Department of Internal Medicine, New York University (NYU) \\ Langone Health, New York, NY, United States, ${ }^{4}$ Department of Rheumatology, Xiangya Hospital, Central South University, \\ Changsha, China, ${ }^{5}$ Department of Surgery, Feinberg School of Medicine, Northwestern University, Chicago, IL, United States
}

Peptidylarginine deiminases (PADs) are a group of enzymes that catalyze posttranslational modifications of proteins by converting arginine residues into citrullines. Among the five members of the PAD family, PAD2 and PAD4 are the most frequently studied because of their abundant expression in immune cells. An increasing number of studies have identified PAD2 as an essential factor in the pathogenesis of many diseases. The successes of preclinical research targeting PAD2 highlights the therapeutic potential of PAD2 inhibition, particularly in sepsis and autoimmune diseases. However, the underlying mechanisms by which PAD2 mediates host immunity remain largely unknown. In this review, we will discuss the role of PAD2 in different types of cell death signaling pathways and the related immune disorders contrasted with functions of PAD4, providing novel therapeutic strategies for PAD2-associated pathology.

Keywords: PAD2, autoimmune diseases, sepsis, NETosis, pyroptosis

\section{HIGHLIGHTS}

- Peptidylarginine deiminase (PAD) enzymes catalyze the conversion of arginine residues to citrulline, regulating activity of host immunity.

- PAD2 plays an important yet different role in immune cells than its isozyme PAD4. Although PAD4 is previously identified to be the key regulator in the formation of neutrophil extracellular traps (NETosis), PAD2 also takes part in NETosis in the absence of PAD4.

- Pad2 deficiency decreases macrophage pyroptosis while Pad4 deficiency increases pyroptosis.

- PAD2, differing from the other PAD family members, citrullinates arginine 1810 (Cit1810) in repeat 31 of the carboxyl-terminal domain of the largest subunit of RNA polymerase II, which enables the efficient transcription of highly expressed genes needed for cell cycle progression, metabolism, and cell proliferation. 


\section{INTRODUCTION}

Peptidylarginine deiminases (PADs) are a group of enzymes that catalyze post-translational modification of proteins by converting arginine residues into citrullines (Figure 1A) $(1,2)$. The PAD family consists of five members: PAD1, PAD2, PAD3, PAD4, and PAD6 (3). As the most widely expressed member, PAD2 can be found in many tissues and organs, including brain (4), spinal cord (4), spleen (5), pancreas (6), skeletal muscles (7), secretory glands, and immune cells $(8,9)$. By citrullinating proteins, PAD2 regulates a number of cellular processes such as gene transcription $(10,11)$, antigen generation (12), extracellular trap formation (also termed ETosis) $(13,14)$, and pyroptosis (15).

ETosis is a described cell death that results in the release of a complex lattice of chromatin containing DNA, histones, and other associated proteins (16-18). These extracellular chromatin webs can entrap and kill microbial organisms. Originally, this phenomenon was described in neutrophils, termed NETosis (Neutrophil Extracellular Traps). However, researchers later found that this mechanism also exists in other cell types such as macrophages, eosinophils, and mast cells (19). Thus, some researchers recommend that the mechanism of this cell death be generalized as "ETosis" (20-22), while others prefer using NETosis or macrophage ETosis (METosis) for the death of specific cell sources.

Similar to the structure of PAD4 (23), the N-terminal of PAD2 consists of two immunoglobulin-like domains, IgG domain 1 (residues 1-115) and IgG domain 2 (residues 116295), and a catalytic domain, the C-terminal (residues 296-665) (24). There are six calcium-binding sites in PAD2 (Ca1-6).

A<smiles>N=C(N)NCCCc1ccccc1</smiles>

Peptidylarginine

B

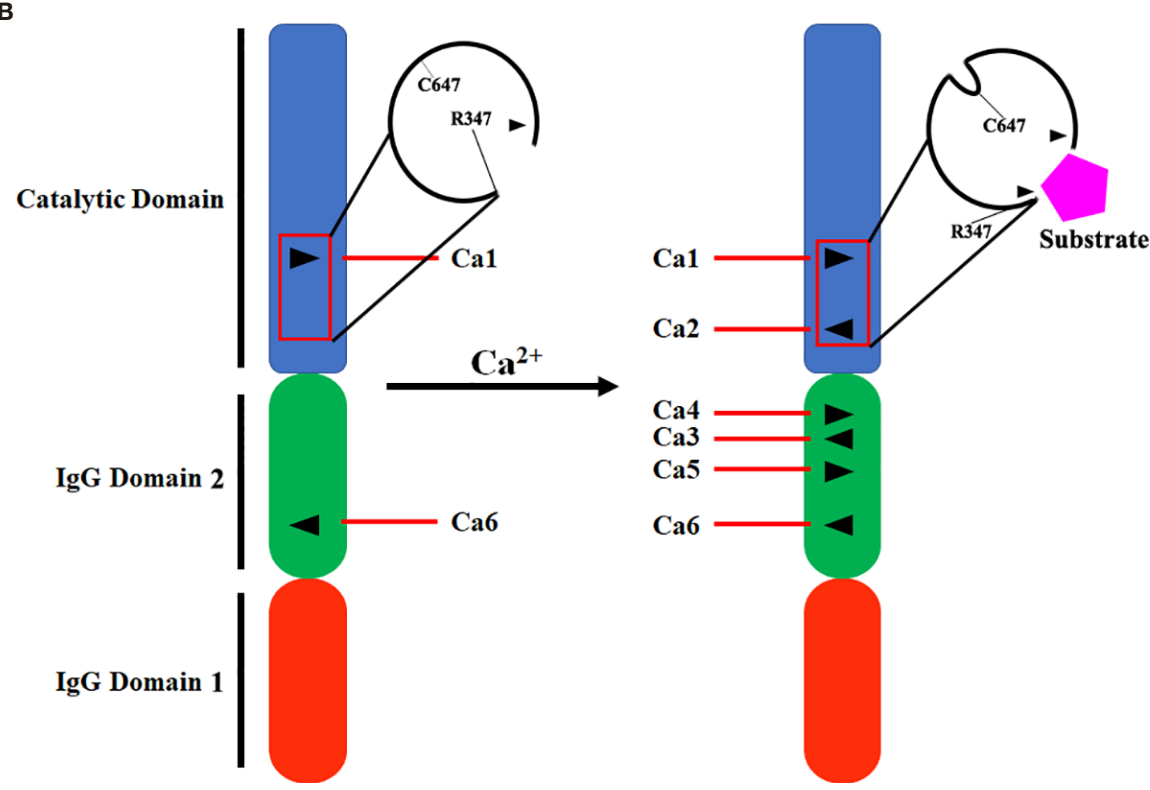

Peptidylcitrulline 
Ca1 and Ca6 are occupied by calcium in both inactivated and activated PAD2. During the activation of PAD2, calcium ions bind to sites Ca3-5. Afterwards, calcium binds to $\mathrm{Ca} 2$, which causes conformational changes at the active site. R347 moves out of the active site, and C647 moves in. As such, a pocket-like structure is generated for substrate binding (Figure 1B). Then, where does the calcium come from for PAD2 activation? A previous study revealed that adenosine triphosphate (ATP)induced PAD2 activation can be dramatically diminished in mast cells cultured in calcium-free media, suggesting that calcium needed for PAD2 activation mainly comes from the extracellular space (25). Zheng et al. also demonstrated that Annexin A5 (ANXA5) can bind to the plasma membrane to facilitate calcium influx and further contribute to PAD2 activation (26). Thus, sufficient extracellular calcium is required for the activation of $\mathrm{PAD} 2$.

The substrates of PAD2 are quite diverse in vivo, including cell structural proteins $(27,28)$, immunomodulating molecules $(29,30)$, and histones (31). For instance, vimentin, which is an important part of the cytoskeleton in skeletal muscles and macrophages, is a PAD2 substrate (28). Another crucial protein for cell structure, actin, can also be citrullinated by PAD2 (27). PAD2 can mediate thrombotic activities via citrullinating antithrombin (32) and fibrinogen (33). PAD2catalyzed citrullination of certain immunomodulating cytokines, such as the chemokine (C-X-C motif) ligand (CXCL) 10 (34), interleukin (IL)-8 (29), and CXCL12 (30) is associated with an altered immune response. Additionally, PAD2 can translocate into nuclei and citrullinate histones, regulating gene transcription $(10,26)$.

Citrullination can change the net charge and increase the hydrophobicity of proteins, which subsequently alters the structures and functions of the proteins (35-39). The effects of citrullination are variable and debated. Hojo-Nakashima et al. revealed that $\mathrm{PAD} 2$ is beneficial as it catalyzes vimentin citrullination in THP-1 cells (a human monocytic cell line) to promote the differentiation and maturation of macrophages (40). By contrast, vimentin citrullinated by PAD2 is identified as an autoantigen in rheumatoid arthritis (RA), exhibiting the potentially detrimental role of PAD2 (32). Apart from vimentin, a large number of proteins are found to trigger autoimmune responses following PAD2-mediated citrullination (32). Interestingly, dysregulation of PAD2 activity has been implicated in many diseases such as RA (41), multiple sclerosis (MS) (42), and neurodegenerative disorders (43). Moreover, previous studies revealed that PAD2-catalyzed citrullination is an essential process during various modes of immune cell death, such as ETosis $(13,14)$ and pyroptosis (15). These modalities of immune cell death may play a major role in the pathogenesis of sepsis and other inflammatory diseases $(44,45)$. Consequently, it is critical to understand the role of PAD2 in host immunity and related diseases. In the following sections, the mechanisms via which PAD2 mediate cellular processes, regulate immune response, and cause diseases will be reviewed and discussed. Understanding the mechanisms of host immunity regulated by PAD2 may ultimately allow for design of novel therapeutic strategies for a multitude of immune disorders.

\section{PAD2 EXPRESSION IN IMMUNE CELLS}

\section{PAD2 in Macrophages}

Macrophages are immune cells which exhibit relatively rich PAD2 expression (9). Macrophages play an important role both in innate and adaptive immunity. Phagocytosis and pyroptosis are two major pathways involved in the pathogen clearance by innate immunity (46-50). Macrophages contribute to adaptive immunity by presenting the antigens of pathogens to T cells (51-53). PAD2 can affect these immune actions through regulating the differentiation of macrophages $(9,40)$. Macrophages are derived from monocytes in circulation. Interestingly, although PAD2 mRNA can be detected in monocytes, it is not translated into PAD2 proteins until the initiation of differentiation (9). Moreover, a previous study revealed that the levels of PAD2 mRNA and proteins exhibit concomitant increases in THP-1 cells during the differentiation into macrophages (40). Nonetheless, the underlying mechanisms through which PAD2 mediate monocyte differentiation remain elusive.

PAD2 also mediates the activation of pyroptosis (Figure 2), another important signaling pathway associated with antipathogen activities in macrophages (15). Pyroptosis is an inflammatory form of macrophage death induced by infection or chemical stimulation and mediated by Caspase-1 and/or Caspase-11 (54). Prior to the activation of Caspase-1, the stimulating signals are sensed by pattern recognition receptors, including NOD-like receptors and AIM2-like receptors, and initiate the assembly of inflammasomes (55-57). During the formation of inflammasomes, a quick increase of protein citrullination can be observed in macrophages (15). Specifically, ASC (apoptosis-associated speck-like protein containing a CARD), a critical component of inflammasomes, is also citrullinated. After PAD2 and PAD4 are dually suppressed by $\mathrm{Cl}$-amidine, a pan-PAD inhibitor (58), the citrullination of ASC is reduced (15). Additionally, the activation of NLRP3 inflammasomes is also dampened, which subsequently diminishes macrophage pyroptosis. In agreement with these findings, our most recent experiments revealed that the knockout of Pad2 in macrophages can decrease Caspase-1 mediated pyroptosis induced by Pseudomonas aeruginosa sepsis (PA-sepsis) (59). In contrast, Pad4 depletion in the macrophages can increase Caspase- 1 mediated pyroptosis in the mouse model of PA-sepsis (59). Therefore, PAD2-mediated ASC citrullination is probably a significant step during inflammasome assembly, which then regulates the activation of Caspase-1 and pyroptosis. Nonetheless, since little effort has been taken to explore the association between PAD2 and pyroptosis, the underlying mechanisms via which PAD2 affects Caspase-1 activation remain to be elucidated.

Aside from pyroptosis, macrophages are also reported to undergo another form of cell death termed METosis (Figure 2) (13), which describes the release of extracellular trap-like structures from macrophages $(20,60)$. Similar to NETs, Macrophage ETs (METs) are found in response to various microorganisms (61). METs are capable of trapping and 


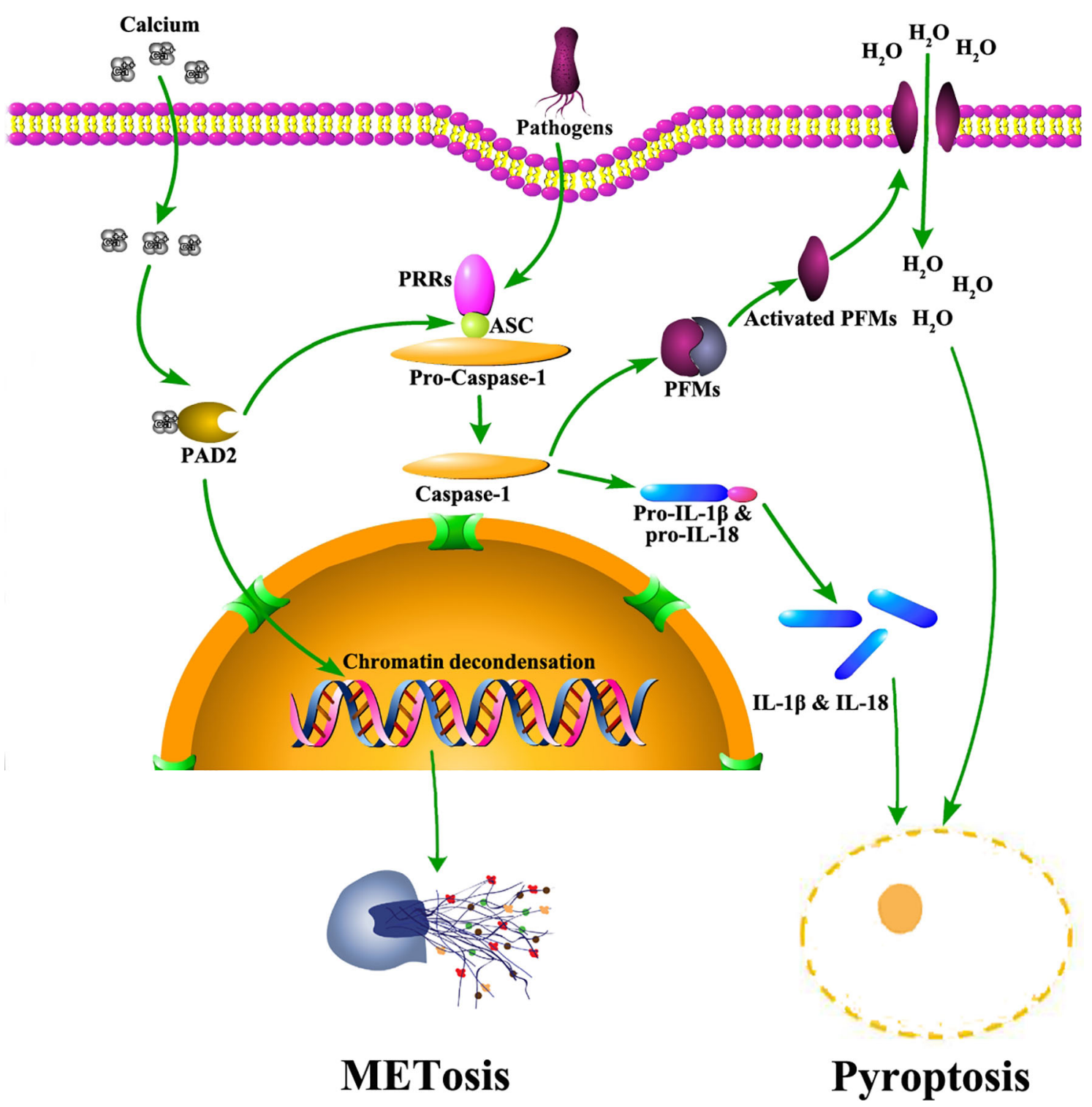

FIGURE 2 | The role of PAD2 in METosis and pyroptosis in macrophages. Pathogens trigger calcium influx into cytoplasm of macrophages. Subsequently, PAD2 is activated due to elevated levels of calcium. Activated PAD2 translocates into the nucleus to induce histone citrullination and chromatin decondensation, leading to METosis. Also, PAD2 mediates pyroptosis via citrullinating ASC. Citrullinated ASC participates in the assembly of inflammasomes which activate Caspase-1.

Caspase- 1 facilitates the maturation of IL-1 $\beta$ and IL-18 via cleaving their precursors. Meanwhile, Caspase- 1 cleaves and activates PFMs which insert into plasma membrane to create pores allowing massive water to flux in. As a result, macrophages swell and rupture to accomplish pyroptosis, releasing mature IL-1 $\beta$ and IL-18. ASC: apoptosis-associated speck-like protein containing a CARD domain; IL, interleukin; METosis, macrophage death with release of macrophage extracellular traps; PAD2, type 2 peptidylarginine deiminase; PFMs, pore forming molecules; PRR, pattern recognition receptor.

immobilizing microbes to assist in microbial clearance (20). Several studies demonstrated that histone hypercitrullination catalyzed by PADs is an essential step during METosis $(13,62)$. Due to the alterations in net charges and structures, hypercitrullinated histones render chromatins more susceptible to decondensation (63). Most prior studies conclude that the process of citrullination is driven by $\mathrm{PAD} 4$, but a study by Mohanan et al. identified PAD2 as a major mediator in tumor necrosis factor (TNF)- $\alpha$ induced MET release from Raw264.7 macrophages (13). Therefore, further work is needed to clarify the association between PAD2 and METosis.

\section{PAD2 in Neutrophils}

Overall, PAD2 seems to have minimal effects on neutrophils due to low expression. The distribution of PAD2 and PAD4 are different in neutrophils. Unlike in macrophages, the PAD that is 
predominantly expressed in neutrophils is PAD4 (64-66). PAD4 exists in granules, plasma membrane, and nucleus, while PAD2 is mainly detected in granules (64). Like macrophages, neutrophils can form NETs to defend against microbial infection (65, 67-69). NETosis also requires PAD-catalyzed histone hypercitrullination, which induces chromatin decondensation (63). In contrast to METosis, the citrullinating process in neutrophils is believed to be entirely mediated by PAD4 (65). However, our recent study found that selective inhibition of PAD2 can significantly decrease the generation of Citrullinated histone H3 (CitH3) in lipopolysaccharide (LPS)stimulated neutrophils (70). The result suggests that PAD2 may also play a role in citrullinating actions within neutrophils. Furthermore, the extracellular release of PAD2 from neutrophils may still be able to citrullinate histone $\mathrm{H} 3$ and fibrinogen (64).

\section{PAD2 in T Cells}

There are two major subtypes of $\mathrm{T}$ cells which are CD4+ $\mathrm{T}$ cells and CD8+ T cells (71). CD8+ T cells directly kill microbeinfected cells or tumor cells (72), while CD4+ T cells usually act indirectly to regulate immune response, thus coined "helper $\mathrm{T}$ cells" (Th) (73). The relationship between CD8+ T cells and PAD2 is not well studied, while several studies revealed that PAD2 can modulate the polarization and functions of CD4+ T cells $(11,74,75)$.

The expression of PAD2 in naïve CD4+ T cells is much lower than that in memory CD4+ $\mathrm{T}$ cells, indicating that PAD2 may have effects on the differentiation of CD4+ T cells (74). Actually, the fate of differentiating CD4+ T cells is decided by two key transcription factors, GATA3 and ROR $\gamma \mathrm{T}$ (76). PAD2 can directly citrullinate these two transcription factors, which changes their DNA binding ability to modulate gene expression (11). PAD2 inhibition decreases the differentiation of Th17 cells but promotes the differentiation of Th2 cells from naïve CD4+ T cells (11). Reversely, PAD2 overexpression in human peripheral blood mononuclear cells reduces Th2 cell polarization and increases Th17 cell polarization (77). Meanwhile, PAD2 regulates the functions of CD4+ T cells (11). PAD2 deficiency enhances cytokine production in Th2 cells but suppress cytokine generation in Th17 cells. Interestingly, although PAD2 is not associated with Th1 polarization, PAD2 inhibition can impair interferon- $\gamma$ production in Th1 cells (11).

In addition to directly altering the functions and polarization of CD4+ T cells, PAD2 can affect T cell activities by citrullinating certain chemotaxins (i.e., CXCL10 and CXCL11) that mediate the chemotaxis of T cells (34). T cells exhibit lower sensitivity to citrullinated CXCL10 and CXCL11. Therefore, fewer T cells will be attracted to inflammation sites, resulting in attenuated inflammatory response.

\section{PAD2 in B Cells}

B cells are a subset of immune cells, which are responsible for antibody production and antigen presentation (78). The expression of PAD2 is low in B cells (79). Nonetheless, PAD2 is probably required for the transition of $\mathrm{B}$ cells to plasma cells, as the knockout of $\mathrm{Pad} 2$ can cause a significant reduction in bone marrow plasma cells in a mouse model of TNF- $\alpha$ induced arthritis (80). Consequently, IgG produced by plasma cells is also decreased in $\mathrm{Pad} 2^{-/-}$mice, which is associated with alleviated severity of TNF- $\alpha$ induced arthritis (80). This may indicate that PAD2 is required for the development of plasma cells. However, given that PAD2citrullinated proteins are antigens for B cells, another explanation may also be established: $\mathrm{Pad} 2$ knockout reduces the generation of citrullinated proteins, thus resulting in decreased activation of B cells. Hence, further work is needed to clarify the role of PAD2 in B cells.

\section{PAD2 in Other Immune Cells}

PAD2 can also interact with other cells to modulate immune response. For example, ATP upregulates the expression of Adamts-9, Rab6b, and TNFRII through activation of PAD2 in mast cells, contributing to the pathogenesis of RA (25). PAD2 and PAD4 inhibition by $\mathrm{Cl}$-amidine also hampers functional maturation of dendritic cells induced by toll-like receptor agonists (81). As evidenced, there remains a paucity of studies exploring the interplay between PAD2 and immune cells. Further clarifying the mechanisms by which PAD2-mediated citrullination participates in immune activities can continue to advance the field in the future clinical applications of PAD2 guided therapies.

\section{PAD2 IN HOST IMMUNITY}

The immunomodulatory effects of PAD2 are mostly exerted by citrullinating key proteins involved in the cell signaling pathways. Thus, PAD2 may display different impacts on host immunity under different circumstances, which is determined by the roles of the citrullinated proteins in these pathways. The involvement of PAD2 in autoimmune diseases reflects its proinflammatory activity. The pathogenesis of RA is associated with elevated levels of PAD2-citrullinated proteins in synovial fluid (82). B cells can recognize the citrullinated epitopes and generate autoantibodies against the citrullinated proteins (83-85). In $70 \%$ of patients with RA, elevated levels of anti-citrullinated protein antibodies (ACPA) can be detected (86). After treatment with antirheumatic drugs, ACPA levels in circulation are significantly reduced correlated with decreased severity of RA $(87,88)$. These results suggest that protein citrullination by PAD2 can trigger an intensified inflammatory response in RA patients. Of note, RA patients who develop antibodies against PAD2 tend to suffer from less severe damage in joints and other organs (89). However, PAD2 sometimes exhibits the ability to inhibit inflammatory response. For example, Loos et al. reported that PAD2-mediated citrullination of CXCL10 and CXCL11 can reduce their chemotactic ability and thus result in diminished accumulation of inflammatory cells (34). PAD2 can also citrullinate certain transcription factors to mediate the differentiation of immune cells. The knockout of $\mathrm{Pad} 2$ gene in mice can cause a shift in maturation of Th cells, which increases the differentiation of Th2 cells but decreases the differentiation of Th17 cells, rendering the mice susceptible to allergic airway inflammation (11). 
The close association between PAD2 and host immunity is partly due to the relatively abundant expression in immune cells $(74,79)$. PAD2 functions as an important factor not only in the differentiation of immune cells, but also in several cell death signaling pathways $(13,15,90,91)$. Although PAD4 is identified to be the key regulator in NETosis $(63,92,93)$, PAD2 may also play a part in the process as NETosis can still occur in the absence of PAD4 (94). Another type of cell death, pyroptosis, which mostly takes place in macrophages, is found to be regulated by PAD2 and PAD4 (15). Additionally, overexpression of PAD2 in Jurkat cells, which are derived from human T lymphocyte cells, can trigger enhanced apoptosis (91). Collectively, these findings indicate that PAD2 has an intimate relationship with immune cells and host immunity.

\section{Infections \\ Sepsis}

Sepsis is characterized by a dysregulated inflammatory response that may result in multi-organ failure (95). The role of PADs in sepsis has been identified in some previous studies (70, 96-98). However, most of them explored the association between PAD4 and sepsis. This was probably due to the critical effects of PAD4 on NETosis, which is believed to be an important signaling pathway involved in the pathogenesis of sepsis (99). The application of pan-PAD inhibitors, which inhibit the activity of both PAD2 and PAD4, can remarkably improve the survival in mouse models of LPS-induced endotoxemia and cecal ligation and puncture (CLP)-induced sepsis (100-102). Nonetheless, when $\mathrm{Pad} 4^{-/-}$mice were used to explore the individual effects of PAD4 on sepsis, researchers found that Pad4-deficiency did not improve survival nor ameliorate bacteremia $(94,98)$. Accordingly, we revealed that a selective PAD4 inhibitor does not affect survival in LPS-induced endotoxic shock (70). Therefore, we began to hypothesize that the protective effects were derived from PAD2 inhibition. As expected, the employment of a selective PAD2 inhibitor in the same model of LPS-induced endotoxic shock significantly increased survival (70). Thereafter, our studies further demonstrated that the knockout of $\mathrm{Pad} 2$ can improve survival in CLP-induced sepsis and PA-sepsis $(59,103)$. Therefore, it can be inferred that PAD2 likely acts as a critical mediator in the pathogenesis of sepsis.

Given the minimal effect of PAD4 on sepsis, it raises questions as to why NETosis is closely related to sepsis and why septic animals can benefit from anti-NET therapies. The pathogenicity of NETs is derived from numerous components such as myeloperoxidase, DNA, and Citrullinated histone H3 (CitH3) (104). Such components are also found in extracellular traps released by other immune cells, such as METs, which are more likely to be mediated by PAD2, as PAD2 is more abundantly expressed in macrophages than PAD4 (61). "AntiNET therapies" are referred to as the clearance of extracellular DNA or CitH3 (105-107), which also eliminate detrimental molecules from other sources including METs at the same time. In contrast, the knockout of PAD4 can only decrease the molecules coming from NETosis. This possibly explains why PAD4 inhibition is not protective during sepsis. In addition, we discovered that selective inhibition of PAD2 can decrease the release of $\mathrm{CitH} 3$ in neutrophils (Figure 3) (70). Furthermore, antibody neutralization of circulation $\mathrm{CitH} 3$, by a commercially available anti-CitH3 antibody, was not shown to attenuate endotoxemia (105). However, administration of the antibody recognizing CitH3 generated from both PAD2 and PAD4 significantly improved survival (105). These findings display the differing effects of PAD2 and PAD4 inhibition during sepsis.

In a mouse model of CLP-induced lethal sepsis, we have newly demonstrated that PAD2 protein is elevated in serum and lung tissue after CLP (103). In septic patients, serum concentrations of PAD2 are positively correlated to lactate $(r=0.5, p=0.04)$ and procalcitonin (PCT) levels $(r=0.67, p=0.003)(108)$. Since lactate and PCT are considered markers for the prognosis and the severity of sepsis $(109,110)$, elevated PAD2 levels in serum may also serve as a future clinical biomarker and predictor of outcomes. Circulating $\mathrm{CitH} 3$ was also found to be positively correlated with blood PAD2 $(r$ values $=0.0452, p<0.001)$ and PAD4 levels $(r$ value $=0.363, p<0.01)$, respectively (108). The levels of PAD2 in bronchoalveolar lavage fluid (BALF) from patients with sepsis and respiratory distress syndrome (ARDS) are also significantly increased compared with those in a healthy control group (108). Furthermore, the Pad2 gene was found to be over-expressed in cells of the BALF of patients with septic specific ARDS. The consistent findings support the possible usage of PAD2 as a biomarker for sepsis specific ARDS and may serve as a distinguishing factor between sepsis specific ARDS and other non-infectious causes of ARDS. PAD2 can mediate the onset of sepsis by directly regulating pyroptosis. We recently found that PA-sepsis induced pyroptosis in macrophages is dramatically decreased in the absence of PAD2, thereby attenuating acute lung injury and improving survival (59). In the murine CLP-sepsis model, Pad2 depletion enhances bacterial clearance, attenuates sepsis-induced vascular permeability of lung and kidney, and improves survival (103). Moreover, we found that macrophages stimulated by LPS undergo diminished Caspase-11-dependent pyroptosis in the absence of PAD2, which can explain how Pad2 knockout improves the outcomes of septic mice (Figure 3) (103). These findings have highlighted the detrimental role of PAD2mediated pyroptosis in the pathogenesis of sepsis (Figure 3). PAD2 also catalyzes the generation of $\mathrm{CitH} 3$ which is recognized as a "danger" signaling molecule $(70,111,112)$. Furthermore, it has been reported that "danger" signaling molecules (i.e., ATP and double strand DNA) can elicit the activation of pyroptosis via the Caspase1 dependent pathway $(113,114)$. Based on this data, we hypothesize that $\mathrm{CitH} 3$ may play a role in activating the pyroptotic pathway and that PAD2 can also modulate pyroptosis in an indirect way. Altogether, PAD2 has the potential as both a biomarker and therapeutic target of sepsis.

Although we have demonstrated the effects of PAD2 activation on sepsis, the mechanisms by which PAD2 activation leads to these downstream effects in sepsis remain poorly understood. A previous study demonstrated that ATP induces PAD2 activity via P2X7 receptors (25). While ATP is required for almost all biological reactions as the universal energy source (115), once host cells are damaged, stressed, or infected by pathogens, intracellular ATP can be released to become extracellular ATP which serves as a key 


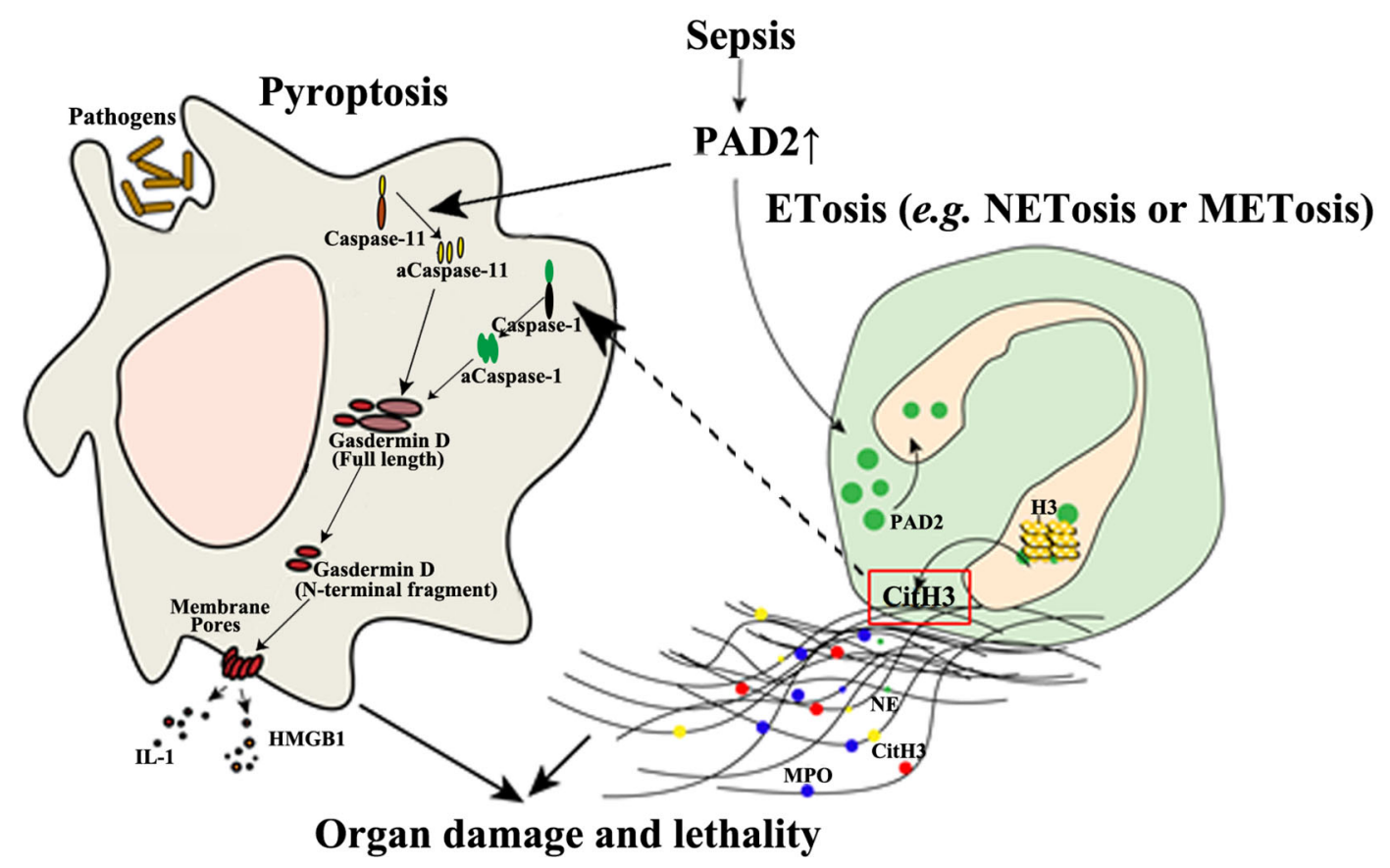

FIGURE 3 | The detrimental effects of PAD2-mediated pyroptosis and ETosis during sepsis. PAD2 facilitates the activation of Caspase-11, a key regulator in noncanonical pyroptosis, and causes macrophage death. In addition, PAD2 can translocate into the nuclei of neutrophils or macrophages and citrullinate histone H3 to induce ETosis. CitH3 generated during this process may further activate the canonical pyroptotic pathway as a danger signal. aCaspase-1/11, activated Caspase-1/ 11; CitH3, Citrullinated histone H3; ETosis, cell death with release of extracellular traps (ETs); H3, Histone H3; HMGB1, high mobility group box 1; IL, interleukin; M/ NETosis, neutrophil/macrophage death with release of extracellular traps; MPO, myeloperoxidase; NE, neutrophil elastase. Lines, pathways already known; Dotted lines, proposed hypothesis for the pathway to elucidated.

“danger" signaling molecule (116-118). Additionally, certain pathogens can also produce and secrete extracellular ATP (119, 120). The extracellular ATP may then bind to P2X7 receptors to induce calcium influx, leading to subsequent PAD2 activation (25). Nonetheless, there is limited evidence supporting that ATP release is responsible for the activation of PAD2 during infections. Thus, further work is required to elucidate the association between infection and PAD2 activity.

\section{Immune Disorders Rheumatoid Arthritis}

The manifestations of RA are characterized by chronic synovitis, systemic inflammation, and the generation of ACPA and rheumatoid factors (121). ACPA recognizes and binds to PAD2/4-citrullinated proteins, including vimentin, keratin, enolase, fibrinogen, and filaggrin $(32,122)$. ACPA can serve as a useful biomarker with high sensitivity and specificity, and is often a predictor of poor prognosis (123-126).

Among all the citrullinated proteins associated with RA, vimentin is the most frequently studied. Vimentin is an intermediate filament protein that plays a significant role in fixing the position of cytosolic organelles (127). Macrophages, which also express vimentin, are found in high levels in synovial fluid aspirates of RA joints (128). During calcium ionophore- induced macrophage apoptosis, vimentin is found to be citrullinated by PADs (90). Given the low expression of PAD4 in macrophages, PAD2 is likely the predominant PAD in the citrullination of vimentin. The cleavage of vimentin also occurs in the presence of calcium during macrophage pyroptosis (129). Since PAD2 is a calcium-dependent enzyme, it can be inferred that vimentin possibly undergoes citrullination prior to macrophage pyroptotic death. However, the mechanisms which citrullinated vimentin is associated with the pathogenesis of RA are not clear. One explanation is that the host loses its self-tolerance to citrullinated vimentin due to hereditary factors, which leads to production of ACPA (122, 130). As a result, massive ACPA-citrullinated vimentin complexes deposit in the joints, causing activation of complement systems leading to prolonged inflammation (131). Although genetic factors are closely related to the incidence of RA, the effects of environmental factors cannot be neglected (132). For example, a number of RA cases were found to be linked with infection (133). Thus, it is possible that infectious agent-induced macrophage death may be the initial step of RA onset. During the death processes of macrophages, vimentin is citrullinated by PAD2 and released. Meanwhile, more macrophages and other immune cells are attracted to the infected sites due to chemotaxis. Thereafter, citrullinated 
vimentin is recognized as an autoantigen which triggers the generation of ACPA. However, this hypothesis cannot explain the pathogenesis of ACPA-negative RA. Therefore, further work is required to understand the complexity of RA.

PAD2 can be detected in synovial fluid from RA patients (134). It was demonstrated that the major sources of PAD2 are inflammatory cells (8). RA patients with higher PAD2 levels in synovial fluid tend to have enhanced disease activity, suggesting that the level of PAD2 in synovial fluid is a potential prognostic indicator (135). Additionally, PAD2 can also be taken as an autoantigen by the host. RA patients who developed autoantibodies against PAD2 are likely to display attenuated joint inflammation and RA-related lung disease (89).

M1 macrophages, which are activated by the classical pathway, can secrete proinflammatory cytokines such as TNF$\alpha$ and IL- 1 and cause joint erosion. While M2 macrophages, which are activated by the alternative pathway, can produce antiinflammatory cytokines (mainly IL-10 and TGF- $\beta$ ), contributing to vasculogenesis and tissue remodeling and repair, as recently observed in systemic sclerosis. Markers for both macrophage phenotypes may coexist on the same cell $(136,137)$. Recent studies have revealed that M1/M2 macrophage imbalance strongly contributes to osteoclastogenesis of RA (138). Eghbalzadeh et al. reported that NETs support macrophage polarization toward an M2 phenotype, displaying antiinflammatory properties. PAD4 deficiency aggravates acute inflammation and increases tissue damage post- acute myocardial infarction, partially due to the lack of NETs (139). It remains largely unknown whether PAD2 affects macrophage polarization.

\section{Multiple Sclerosis}

MS is an autoimmune disorder in central nervous system characterized by chronic demyelination of nerve cells (140). Patients with MS usually suffer from loss of sensitivity, changes in sensation, difficulties in coordination or problems with vision (141). The effects of PAD2 on the pathogenesis of MS remain in debate. Researchers revealed that citrullination of myelin basic proteins (MBP) is increased in MS patients (42, 142, 143). Overexpression of PAD2 in mice leads to MBP hypercitrullination and myelin loss in central nervous system (144). Hypercitrullination will not only decrease the stability of MBP, but also put MBP at higher risks of being attacked by $\mathrm{T}$ cells $(28,75)$. Th17 cells, a subtype of T cell, shows enhanced reactivity to citrullinated $\mathrm{MBP}$ (75). As mentioned above, PAD2 can facilitate the polarization of CD4+ T cells into Th17 cells (11). Thus, PAD2 plays a critical role in MS pathogenesis. In line with these findings, a study demonstrated that PAD2 inhibition can attenuate disease severity in animal models mimicking MS (145). On the contrary, a study reported that deletion of Pad2 gene in mice decreased levels of citrullinated MBP but did not reduce the incidence rate of experimental autoimmune encephalomyelitis (146). A recent study discovered that PAD2mediated citrullination is indispensable during the differentiation and myelination of oligodendrocytes (147).
Knockout of $\mathrm{Pad} 2$ in mice will result in motor dysfunction and even decreased myelination in axons (147). Therefore, it is critical to keep a balanced PAD2 level in central nervous system as it maintains the normal structure and functions of nerve cells and further studies should continue to elucidate the role of PAD2 on MS.

\section{Cancers}

Currently, PAD2 is implicated in skin tumors (148), breast cancer (10), colorectal cancer (149), and glioblastoma multiforme $(150,151)$. The intimate relationship between PAD2 and tumors is likely due to the role of PAD2 in modulating gene transcription. PAD2 is the only PAD that citrullinates arginine1810 (Cit1810) in repeat 31 of the carboxyl-terminal domain (CTD) of the largest subunit of RNA polymerase II (RNAP2) (152). Cit1810 is crucial for RNAP2 to overcome the pausing barrier close to the transcription start site, which enables the efficient transcription of highly expressed genes needed for cell cycle progression, metabolism, and cell proliferation (152).

The effects of PAD2 on the development of different tumors are not the same. For example, overexpression of PAD2 has been shown to augment the malignancy of skin tumors (153), while increased PAD2 expression has been linked to improved survival in patients with estrogen receptor (ER)-positive breast cancer (112). However, upregulated PAD2 expression in breast cancer is associated with resistance to tamoxifen treatment (154). These findings make PAD2 a mysterious modulator in tumorigenesis. In the pathogenesis of breast cancer and glioblastoma multiforme, PAD2 modulates gene transcription via citrullinating histones $(112,151)$. In colorectal cancer, however, PAD2 prevents tumor progression by citrullinating $\beta$-catenin thus inhibiting the Wnt signaling pathway. PAD2 inhibition will increase the sensitivity of breast cancer cells to tamoxifen (154), while the knockout of $\mathrm{Pad} 2$ will induce great resistance to nitazoxanide in colorectal cancer cells (149). More work is needed to investigate the involvement of PAD2 in other tumors (149).

The therapeutic potential and applications of PAD2 in cancer remains to be further clarified. However, given the role of PAD2 in tumorigenesis and response to chemotherapy, PAD2 will continue to be a biomarker and target of continued interest in the era of personalized cancer care.

\section{CONCLUSIONS AND FUTURE PERSPECTIVES}

Citrullination is a posttranslational protein modification catalyzed by PADs and is involved in host immunity. PAD2 has wide-reaching roles through its citrullination of a variety of target proteins. Dysregulated activity of PAD2 is associated with a series of immune disorders including sepsis, RA, MS, and tumor formation (Figure 4). In this review, we have summarized PAD2 specific functions on cell death control, transcription 


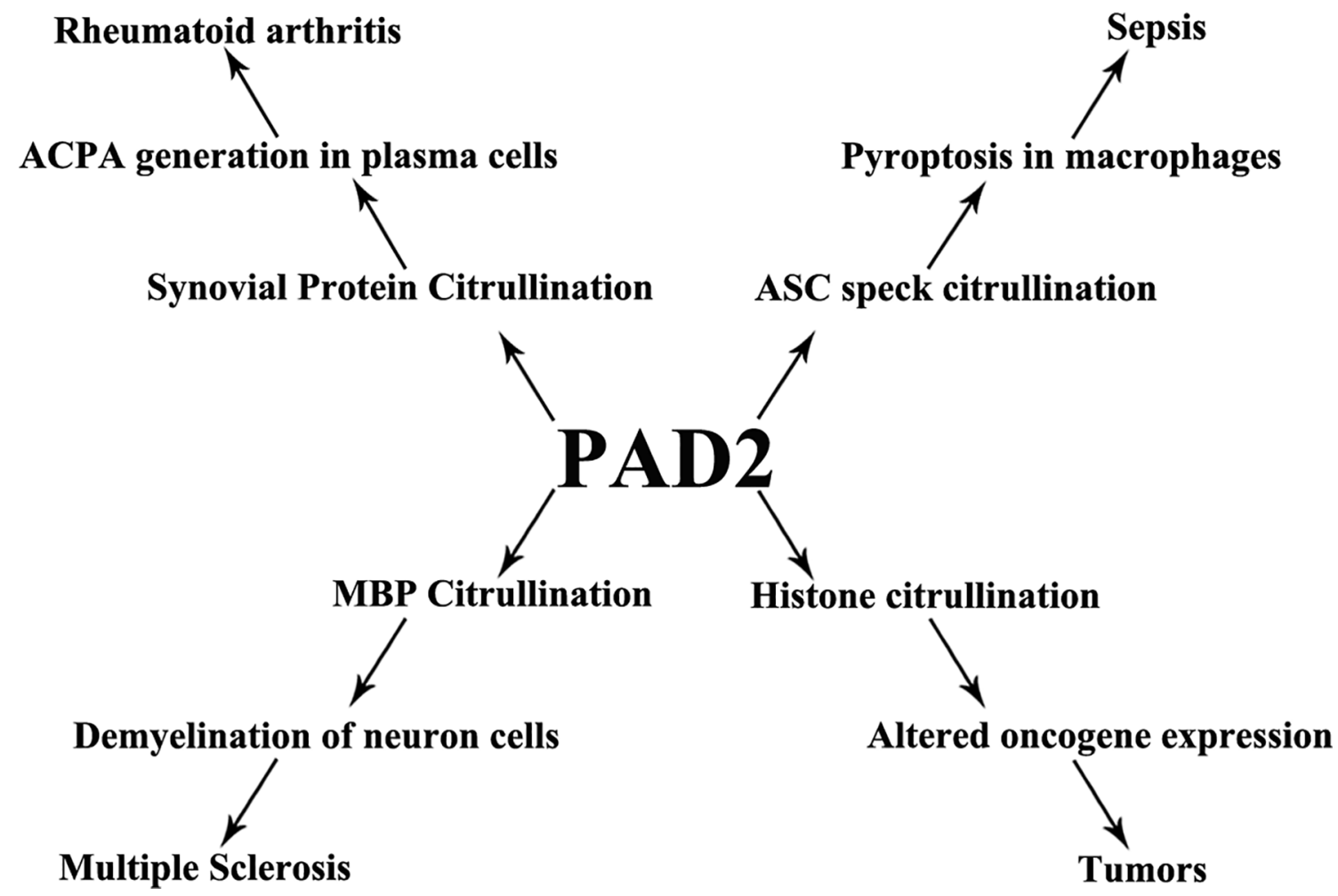

FIGURE 4 | PAD2 and immune disorders. A schematic view showing that PAD2 is associated with a number of diseases and the possible mechanisms underlying pathogenesis. ACPA, anti-citrullinated protein antibodies; ASC, apoptosis-associated speck-like protein containing a CARD domain; MBP, myelin basic protein.

regulation by citrullination of arginine 26 on histone H3 (e.g., sepsis, tumor), and citrullination of vimentin (e.g., RA). We highlight several citrullinated proteins to demonstrate the contributions of PAD2-mediated protein citrullination to RA, sepsis, and cancer within each specific environment. Given that $\mathrm{CitH} 3$ is also found to be a biomarker in patients with cancers $(155,156)$, more epigenetic studies are needed to explore if and how citrullination of histone $\mathrm{H} 3$ interferes with transcription factors to regulate RA, sepsis, and cancers. We propose that PAD2 is a promising novel biomarker and therapeutic target for a broad spectrum of diseases including autoimmune and inflammatory diseases, sepsis, MS, and several types of cancer.

\section{REFERENCES}

1. Wang S, Wang Y. Peptidylarginine Deiminases in Citrullination, Gene Regulation, Health and Pathogenesis. Biochim Biophys Acta (2013) 1829 (10):1126-35. doi: 10.1016/j.bbagrm.2013.07.003

2. Vossenaar ER, Zendman AJ, van Venrooij WJ, Pruijn GJ. PAD, a Growing Family of Citrullinating Enzymes: Genes, Features and Involvement in Disease. Bioessays (2003) 25(11):1106-18. doi: 10.1002/bies.10357

3. Chavanas S, Mechin MC, Takahara H, Kawada A, Nachat R, Serre G, et al. Comparative Analysis of the Mouse and Human Peptidylarginine Deiminase Gene Clusters Reveals Highly Conserved non-Coding Segments and a New Human Gene, PADI6. Gene (2004) 330:19-27. doi: 10.1016/j.gene.2003.12.038

\section{AUTHOR CONTRIBUTIONS}

ZW and YL drafted the manuscript. PL, YT, WO, JH, HA, and YL made significant revisions to the manuscript. All authors contributed to the article and approved the submitted version.

\section{FUNDING}

This work was funded by grants from the National Institute of Health R01 (Grant\# RHL155116A) to YL and HA, and the Jointof-Institute (Grant\# U068874) to YL. 
7. Cherrington BD, Morency E, Struble AM, Coonrod SA, Wakshlag JJ. Potential Role for Peptidylarginine Deiminase 2 (PAD2) in Citrullination of Canine Mammary Epithelial Cell Histones. PLoS One (2010) 5(7):e11768. doi: 10.1371/journal.pone.0011768

8. Foulquier C, Sebbag M, Clavel C, Chapuy-Regaud S, Al Badine R, Mechin MC, et al. Peptidyl Arginine Deiminase Type 2 (PAD-2) and PAD-4 But Not PAD-1, PAD-3, and PAD-6 are Expressed in Rheumatoid Arthritis Synovium in Close Association With Tissue Inflammation. Arthritis Rheum (2007) 56(11):3541-53. doi: 10.1002/art.22983

9. Vossenaar ER, Radstake TR, van der Heijden A, van Mansum MA, Dieteren C, de Rooij DJ, et al. Expression and Activity of Citrullinating Peptidylarginine Deiminase Enzymes in Monocytes and Macrophages. Ann Rheum Dis (2004) 63(4):373-81. doi: 10.1136/ard.2003.012211

10. Cherrington BD, Zhang X, McElwee JL, Morency E, Anguish LJ, Coonrod SA. Potential Role for PAD2 in Gene Regulation in Breast Cancer Cells. PloS One (2012) 7(7):e41242. doi: 10.1371/journal.pone.0041242

11. Sun B, Chang HH, Salinger A, Tomita B, Bawadekar M, Holmes CL, et al. Reciprocal Regulation of Th2 and Th17 Cells by PAD2-Mediated Citrullination. JCI Insight (2019) 4(22):e129687. doi: 10.1172/ jci.insight. 129687

12. Arnoux F, Mariot C, Peen E, Lambert NC, Balandraud N, Roudier J, et al. Peptidyl Arginine Deiminase Immunization Induces Anticitrullinated Protein Antibodies in Mice With Particular MHC Types. Proc Natl Acad Sci U S A (2017) 114(47):E10169-77. doi: 10.1073/pnas.1713112114

13. Mohanan S, Horibata S, McElwee JL, Dannenberg AJ, Coonrod SA. Identification of Macrophage Extracellular Trap-Like Structures in Mammary Gland Adipose Tissue: A Preliminary Study. Front Immunol (2013) 4:67. doi: 10.3389/fimmu.2013.00067

14. Boe DM, Curtis BJ, Chen MM, Ippolito JA, Kovacs EJ. Extracellular Traps and Macrophages: New Roles for the Versatile Phagocyte. J Leukoc Biol (2015) 97(6):1023-35. doi: 10.1189/jlb.4RI1014-521R

15. Mishra N, Schwerdtner L, Sams K, Mondal S, Ahmad F, Schmidt RE, et al. Cutting Edge: Protein Arginine Deiminase 2 and 4 Regulate NLRP3 Inflammasome-Dependent IL-1beta Maturation and ASC Speck Formation in Macrophages. J Immunol (2019) 203(4):795-800. doi: 10.4049/jimmunol.1800720

16. Amulic B, Hayes G. Neutrophil Extracellular Traps. Curr Biol (2011) 21(9): R297-8. doi: 10.1016/j.cub.2011.03.021

17. Liu CL, Tangsombatvisit S, Rosenberg JM, Mandelbaum G, Gillespie EC, Gozani OP, et al. Specific Post-Translational Histone Modifications of Neutrophil Extracellular Traps as Immunogens and Potential Targets of Lupus Autoantibodies. Arthritis Res Ther (2012) 14(1):R25. doi: 10.1186/ar3707

18. Saffarzadeh M, Juenemann C, Queisser MA, Lochnit G, Barreto G, Galuska SP, et al. Neutrophil Extracellular Traps Directly Induce Epithelial and Endothelial Cell Death: A Predominant Role of Histones. PLoS One (2012) 7 (2):e32366. doi: 10.1371/journal.pone.0032366

19. Aulik NA, Hellenbrand KM, Czuprynski CJ. Mannheimia Haemolytica and its Leukotoxin Cause Macrophage Extracellular Trap Formation by Bovine Macrophages. Infect Immun (2012) 80(5):1923-33. doi: 10.1128/IAI.06120-11

20. Loureiro A, Pais C, Sampaio P. Relevance of Macrophage Extracellular Traps in C. Albicans Killing. Front Immunol (2019) 10:2767. doi: 10.3389/ fimmu.2019.02767

21. Fukuchi M, Miyabe Y, Furutani C, Saga T, Moritoki Y, Yamada T, et al. How to Detect Eosinophil ETosis (EETosis) and Extracellular Traps. Allergol Int (2021) 70(1):19-29. doi: 10.1016/j.alit.2020.10.002

22. Nija RJ, Sanju S, Sidharthan N, Mony U. Extracellular Trap by Blood Cells: Clinical Implications. Tissue Eng Regener Med (2020) 17(2):141-53. doi: 10.1007/s13770-020-00241-z

23. Arita K, Hashimoto H, Shimizu T, Nakashima K, Yamada M, Sato M. Structural Basis for $\mathrm{Ca}(2+)$-Induced Activation of Human PAD4. Nat Struct Mol Biol (2004) 11(8):777-83. doi: 10.1038/nsmb799

24. Slade DJ, Fang P, Dreyton CJ, Zhang Y, Fuhrmann J, Rempel D, et al. Protein Arginine Deiminase 2 Binds Calcium in an Ordered Fashion: Implications for Inhibitor Design. ACS Chem Biol (2015) 10(4):1043-53. doi: 10.1021/cb500933j

25. Arandjelovic S, McKenney KR, Leming SS, Mowen KA. ATP Induces Protein Arginine Deiminase 2-Dependent Citrullination in Mast Cells Through the P2X7 Purinergic Receptor. J Immunol (2012) 189(8):411222. doi: $10.4049 /$ jimmunol.1201098
26. Zheng L, Nagar M, Maurais AJ, Slade DJ, Parelkar SS, Coonrod SA, et al. Calcium Regulates the Nuclear Localization of Protein Arginine Deiminase 2. Biochemistry (2019) 58(27):3042-56. doi: 10.1021/acs.biochem.9b00225

27. Darrah E, Rosen A, Giles JT, Andrade F. Peptidylarginine Deiminase 2, 3 and 4 Have Distinct Specificities Against Cellular Substrates: Novel Insights Into Autoantigen Selection in Rheumatoid Arthritis. Ann Rheum Dis (2012) 71(1):92-8. doi: 10.1136/ard.2011.151712

28. Alghamdi M, Alasmari D, Assiri A, Mattar E, Aljaddawi AA, Alattas SG, et al. An Overview of the Intrinsic Role of Citrullination in Autoimmune Disorders. J Immunol Res (2019) 2019:7592851. doi: 10.1155/2019/7592851

29. Proost P, Loos T, Mortier A, Schutyser E, Gouwy M, Noppen S, et al. Citrullination of CXCL8 by Peptidylarginine Deiminase Alters Receptor Usage, Prevents Proteolysis, and Dampens Tissue Inflammation. J Exp Med (2008) 205(9):2085-97. doi: 10.1084/jem.20080305

30. Janssens R, Struyf S, Proost P. The Unique Structural and Functional Features of CXCL12. Cell Mol Immunol (2018) 15(4):299-311. doi: 10.1038/ cmi.2017.107

31. Zhang X, Bolt M, Guertin MJ, Chen W, Zhang S, Cherrington BD, et al. Peptidylarginine Deiminase 2-Catalyzed Histone H3 Arginine 26 Citrullination Facilitates Estrogen Receptor Alpha Target Gene Activation. Proc Natl Acad Sci U S A (2012) 109(33):13331-6. doi: 10.1073/pnas. 1203280109

32. Tilvawala R, Nguyen SH, Maurais AJ, Nemmara VV, Nagar M, Salinger AJ, et al. The Rheumatoid Arthritis-Associated Citrullinome. Cell Chem Biol (2018) 25(6):691-704.e6. doi: 10.1016/j.chembiol.2018.03.002

33. Damgaard D, Bawadekar M, Senolt L, Stensballe A, Shelef MA, Nielsen CH. Relative Efficiencies of Peptidylarginine Deiminase 2 and 4 in Generating Target Sites for Anti-Citrullinated Protein Antibodies in Fibrinogen, AlphaEnolase and Histone H3. PLoS One (2018) 13(8):e0203214. doi: 10.1371/ journal.pone. 0203214

34. Loos T, Mortier A, Gouwy M, Ronsse I, Put W, Lenaerts JP, et al Citrullination of CXCL10 and CXCL11 by Peptidylarginine Deiminase: A Naturally Occurring Posttranslational Modification of Chemokines and New Dimension of Immunoregulation. Blood (2008) 112(7):2648-56. doi: 10.1182/blood-2008-04-149039

35. Tarcsa E, Marekov LN, Mei G, Melino G, Lee SC, Steinert PM. Protein Unfolding by Peptidylarginine Deiminase. Substrate Specificity and Structural Relationships of the Natural Substrates Trichohyalin and Filaggrin. J Biol Chem (1996) 271 (48):30709-16. doi: 10.1074/jbc.271.48.30709

36. Wang Y, Wysocka J, Sayegh J, Lee YH, Perlin JR, Leonelli L, et al. Human PAD4 Regulates Histone Arginine Methylation Levels via Demethylimination. Science (2004) 306(5694):279-83. doi: 10.1126/ science. 1101400

37. Fert-Bober J, Giles JT, Holewinski RJ, Kirk JA, Uhrigshardt H, Crowgey EL, et al. Citrullination of Myofilament Proteins in Heart Failure. Cardiovasc Res (2015) 108(2):232-42. doi: 10.1093/cvr/cvv185

38. Jang B, Jeon YC, Choi JK, Park M, Kim JI, Ishigami A, et al. Peptidylarginine Deiminase Modulates the Physiological Roles of Enolase via Citrullination: Links Between Altered Multifunction of Enolase and Neurodegenerative Diseases. Biochem J (2012) 445(2):183-92. doi: 10.1042/BJ20120025

39. Cuthbert GL, Daujat S, Snowden AW, Erdjument-Bromage H, Hagiwara T, Yamada M, et al. Histone Deimination Antagonizes Arginine Methylation. Cell (2004) 118(5):545-53. doi: 10.1016/j.cell.2004.08.020

40. Hojo-Nakashima I, Sato R, Nakashima K, Hagiwara T, Yamada M. Dynamic Expression of Peptidylarginine Deiminase 2 in Human Monocytic Leukaemia THP-1 Cells During Macrophage Differentiation. J Biochem (2009) 146(4):471-9. doi: 10.1093/jb/mvp097

41. Curran AM, Naik P, Giles JT, Darrah E. PAD Enzymes in Rheumatoid Arthritis: Pathogenic Effectors and Autoimmune Targets. Nat Rev Rheumatol (2020) 16(6):301-15. doi: 10.1038/s41584-020-0409-1

42. Calabrese R, Zampieri M, Mechelli R, Annibali V, Guastafierro T, Ciccarone F, et al. Methylation-Dependent PAD2 Upregulation in Multiple Sclerosis Peripheral Blood. Mult Scler (2012) 18(3):299-304. doi: 10.1177/ 1352458511421055

43. Arif M, Kato T. Increased Expression of PAD2 After Repeated Intracerebroventricular Infusions of Soluble Abeta(25-35) in the Alzheimer's Disease Model Rat Brain: Effect of Memantine. Cell Mol Biol Lett (2009) 14(4):703-14. doi: 10.2478/s11658-009-0029-x 
44. Guimaraes-Costa AB, Nascimento MT, Wardini AB, Pinto-da-Silva LH, Saraiva EM. ETosis: A Microbicidal Mechanism Beyond Cell Death. J Parasitol Res (2012) 2012:929743. doi: 10.1155/2012/929743

45. Aglietti RA, Dueber EC. Recent Insights Into the Molecular Mechanisms Underlying Pyroptosis and Gasdermin Family Functions. Trends Immunol (2017) 38(4):261-71. doi: 10.1016/j.it.2017.01.003

46. Hirayama D, Iida T, Nakase H. The Phagocytic Function of MacrophageEnforcing Innate Immunity and Tissue Homeostasis. Int J Mol Sci (2017) 19 (1):92. doi: 10.3390/ijms19010092

47. Aderem A, Underhill DM. Mechanisms of Phagocytosis in Macrophages. Annu Rev Immunol (1999) 17:593-623. doi: 10.1146/annurev.immunol.17.1.593

48. Miao EA, Leaf IA, Treuting PM, Mao DP, Dors M, Sarkar A, et al. Caspase-1Induced Pyroptosis is an Innate Immune Effector Mechanism Against Intracellular Bacteria. Nat Immunol (2010) 11(12):1136-42. doi: 10.1038/ni.1960

49. Lacey CA, Mitchell WJ, Dadelahi AS, Skyberg JA. Caspase-1 and Caspase-11 Mediate Pyroptosis, Inflammation, and Control of Brucella Joint Infection. Infect Immun (2018) 86(9):e00361-18. doi: 10.1128/IAI.00361-18

50. Jorgensen I, Zhang Y, Krantz BA, Miao EA. Pyroptosis Triggers Pore-Induced Intracellular Traps (PITs) That Capture Bacteria and Lead to Their Clearance by Efferocytosis. J Exp Med (2016) 213(10):2113-28. doi: 10.1084/jem.20151613

51. Ziegler K, Unanue ER. Identification of a Macrophage Antigen-Processing Event Required for I-Region-Restricted Antigen Presentation to $\mathrm{T}$ Lymphocytes. J Immunol (1981) 127(5):1869-75.

52. Unanue ER. Antigen-Presenting Function of the Macrophage. Annu Rev Immunol (1984) 2:395-428. doi: 10.1146/annurev.iy.02.040184.002143

53. Martinez-Pomares L, Gordon S. Antigen Presentation the Macrophage Way. Cell (2007) 131(4):641-3. doi: 10.1016/j.cell.2007.10.046

54. Shi J, Gao W, Shao F. Pyroptosis: Gasdermin-Mediated Programmed Necrotic Cell Death. Trends Biochem Sci (2017) 42(4):245-54. doi: 10.1016/j.tibs.2016.10.004

55. Gao J, Peng S, Shan X, Deng G, Shen L, Sun J, et al. Inhibition of AIM2 Inflammasome-Mediated Pyroptosis by Andrographolide Contributes to Amelioration of Radiation-Induced Lung Inflammation and Fibrosis. Cell Death Dis (2019) 10(12):957. doi: 10.1038/s41419-019-2195-8

56. Miao EA, Ernst RK, Dors M, Mao DP, Aderem A. Pseudomonas Aeruginosa Activates Caspase 1 Through Ipaf. Proc Natl Acad Sci U S A (2008) 105 (7):2562-7. doi: 10.1073/pnas.0712183105

57. Kelley N, Jeltema D, Duan Y, He Y. The NLRP3 Inflammasome: An Overview of Mechanisms of Activation and Regulation. Int $\mathrm{J} \mathrm{Mol} \mathrm{Sci}$ (2019) 20(13):3328. doi: 10.3390/ijms20133328

58. Li Y, Liu Z, Liu B, Zhao T, Chong W, Wang Y, et al. Citrullinated Histone H3: A Novel Target for the Treatment of Sepsis. Surgery (2014) 156(2):22934. doi: 10.1016/j.surg.2014.04.009

59. Wu Z, Tian Y, Alam HB, Li P, Duan X, Williams AM, et al. Peptidylarginine Deiminases 2 Mediates Caspase-1-Associated Lethality in Pseudomonas Aeruginosa Pneumonia-Induced Sepsis. J Infect Dis (2021) 223(6):1093102. doi: 10.1093/infdis/jiaa475

60. Okubo K, Kurosawa M, Kamiya M, Urano Y, Suzuki A, Yamamoto K, et al. Macrophage Extracellular Trap Formation Promoted by Platelet Activation is a Key Mediator of Rhabdomyolysis-Induced Acute Kidney Injury. Nat Med (2018) 24(2):232-8. doi: 10.1038/nm.4462

61. Doster RS, Rogers LM, Gaddy JA, Aronoff DM. Macrophage Extracellular Traps: A Scoping Review. J Innate Immun (2018) 10(1):3-13. doi: 10.1159/000480373

62. Wong KW, Jacobs WRJr. Mycobacterium Tuberculosis Exploits Human Interferon Gamma to Stimulate Macrophage Extracellular Trap Formation and Necrosis. J Infect Dis (2013) 208(1):109-19. doi: 10.1093/infdis/jit097

63. Wang Y, Li M, Stadler S, Correll S, Li P, Wang D, et al. Histone Hypercitrullination Mediates Chromatin Decondensation and Neutrophil Extracellular Trap Formation. J Cell Biol (2009) 184(2):205-13. doi: 10.1083/ jcb.200806072

64. Zhou Y, Chen B, Mittereder N, Chaerkady R, Strain M, An LL, et al. Spontaneous Secretion of the Citrullination Enzyme PAD2 and Cell Surface Exposure of PAD4 by Neutrophils. Front Immunol (2017) 8:1200. doi: 10.3389/fimmu.2017.01200

65. Rohrbach AS, Slade DJ, Thompson PR, Mowen KA. Activation of PAD4 in NET Formation. Front Immunol (2012) 3:360. doi: 10.3389/fimmu.2012.00360

66. Demers M, Wong SL, Martinod K, Gallant M, Cabral JE, Wang Y, et al. Priming of Neutrophils Toward NETosis Promotes Tumor Growth. Oncoimmunology (2016) 5(5):e1134073. doi: 10.1080/2162402X.2015.1134073
67. Schilcher K, Andreoni F, Uchiyama S, Ogawa T, Schuepbach RA, Zinkernagel AS. Increased Neutrophil Extracellular Trap-Mediated Staphylococcus Aureus Clearance Through Inhibition of Nuclease Activity by Clindamycin and Immunoglobulin. J Infect Dis (2014) 210(3):473-82. doi: 10.1093/infdis/jiu091

68. Araujo CV, Campbell C, Goncalves-de-Albuquerque CF, Molinaro R, Cody MJ, Yost CC, et al. A PPARgamma AGONIST ENHANCES BACTERIAL CLEARANCE THROUGH NEUTROPHIL EXTRACELLULAR TRAP FORMATION AND IMPROVES SURVIVAL IN SEPSIS. Shock (2016) 45 (4):393-403. doi: 10.1097/SHK.0000000000000520

69. Brinkmann V, Reichard U, Goosmann C, Fauler B, Uhlemann Y, Weiss DS, et al. Neutrophil Extracellular Traps Kill Bacteria. Science (2004) 303 (5663):1532-5. doi: 10.1126/science.1092385

70. Wu Z, Deng Q, Pan B, Alam HB, Tian Y, Bhatti UF, et al. Inhibition of PAD2 Improves Survival in a Mouse Model of Lethal LPS-Induced Endotoxic Shock Inflammation (2020) 43(4):1436-45. doi: 10.1007/s10753-020-01221-0

71. Golubovskaya V, Wu L. Different Subsets of T Cells, Memory, Effector Functions, and CAR-T Immunotherapy. Cancers (Basel) (2016) 8(3):36. doi: $10.3390 /$ cancers8030036

72. Zhang N, Bevan MJ. CD8(+) T Cells: Foot Soldiers of the Immune System. Immunity (2011) 35(2):161-8. doi: 10.1016/j.immuni.2011.07.010

73. Tubo NJ, Jenkins MK. CD4+ T Cells: Guardians of the Phagosome. Clin Microbiol Rev (2014) 27(2):200-13. doi: 10.1128/CMR.00097-13

74. Liu Y, Lightfoot YL, Seto N, Carmona-Rivera C, Moore E, Goel R, et al Peptidylarginine Deiminases 2 and 4 Modulate Innate and Adaptive Immune Responses in TLR-7-Dependent Lupus. JCI Insight (2018) 3(23): e124729. doi: 10.1172/jci.insight.124729

75. Carrillo-Vico A, Leech MD, Anderton SM. Contribution of Myelin Autoantigen Citrullination to T Cell Autoaggression in the Central Nervous System. J Immunol (2010) 184(6):2839-46. doi: 10.4049/jimmunol.0903639

76. Vahedi G, C Poholek A, Hand TW, Laurence A, Kanno Y, O'Shea JJ, et al Helper T-Cell Identity and Evolution of Differential Transcriptomes and Epigenomes. Immunol Rev (2013) 252(1):24-40. doi: 10.1111/imr.12037

77. Chang HH, Liu GY, Dwivedi N, Sun B, Okamoto Y, Kinslow JD, et al. A Molecular Signature of Preclinical Rheumatoid Arthritis Triggered by Dysregulated PTPN22. JCI Insight (2016) 1(17):e90045. doi: 10.1172/ jci.insight. 90045

78. LeBien TW, Tedder TF. B Lymphocytes: How They Develop and Function. Blood (2008) 112(5):1570-80. doi: 10.1182/blood-2008-02-078071

79. Ireland JM, Unanue ER. Autophagy in Antigen-Presenting Cells Results in Presentation of Citrullinated Peptides to CD4 T Cells. J Exp Med (2011) 208 (13):2625-32. doi: 10.1084/jem.20110640

80. Bawadekar M, Shim D, Johnson CJ, Warner TF, Rebernick R, Damgaard D, et al. Peptidylarginine Deiminase 2 is Required for Tumor Necrosis Factor AlphaInduced Citrullination and Arthritis, But Not Neutrophil Extracellular Trap Formation. J Autoimmun (2017) 80:39-47. doi: 10.1016/j.jaut.2017.01.006

81. Jang B, Kim HW, Kim JS, Kim WS, Lee BR, Kim S, et al. Peptidylarginine Deiminase Inhibition Impairs Toll-Like Receptor Agonist-Induced Functional Maturation of Dendritic Cells, Resulting in the Loss of T CellProliferative Capacity: A Partial Mechanism With Therapeutic Potential in Inflammatory Settings. J Leukoc Biol (2015) 97(2):351-62. doi: 10.1189/ jlb.3A0314-142RR

82. Vossenaar ER, Nijenhuis S, Helsen MM, van der Heijden A, Senshu T, van den Berg WB, et al. Citrullination of Synovial Proteins in Murine Models of Rheumatoid Arthritis. Arthritis Rheum (2003) 48(9):2489-500. doi: 10.1002/art.11229

83. Masson-Bessiere C, Sebbag M, Durieux JJ, Nogueira L, Vincent C, GirbalNeuhauser E, et al. In the Rheumatoid Pannus, Anti-Filaggrin Autoantibodies are Produced by Local Plasma Cells and Constitute a Higher Proportion of IgG Than in Synovial Fluid and Serum. Clin Exp Immunol (2000) 119(3):544-52. doi: 10.1046/j.1365-2249.2000.01171.x

84. Reparon-Schuijt CC, van Esch WJ, van Kooten C, Schellekens GA, de Jong BA, van Venrooij WJ, et al. Secretion of Anti-Citrulline-Containing Peptide Antibody by B Lymphocytes in Rheumatoid Arthritis. Arthritis Rheum (2001) 44(1):41-7. doi: 10.1002/1529-0131(200101)44:1<41::AID-ANR6>3.0.CO;2-0

85. Lelieveldt L, Kristyanto H, Pruijn GJM, Scherer HU, Toes REM, Bonger KM. Sequential Prodrug Strategy To Target and Eliminate ACPA-Selective Autoreactive B Cells. Mol Pharm (2018) 15(12):5565-73. doi: 10.1021/ acs.molpharmaceut.8b00741 
86. Schellekens GA, Visser H, de Jong BA, van den Hoogen FH, Hazes JM, Breedveld FC, et al. The Diagnostic Properties of Rheumatoid Arthritis Antibodies Recognizing a Cyclic Citrullinated Peptide. Arthritis Rheum (2000) 43(1):155-63. doi: 10.1002/1529-0131(200001)43:1<155::AIDANR20 $>3.0 . \mathrm{CO} ; 2-3$

87. Seegobin SD, Ma MH, Dahanayake C, Cope AP, Scott DL, Lewis CM, et al. ACPA-Positive and ACPA-Negative Rheumatoid Arthritis Differ in Their Requirements for Combination DMARDs and Corticosteroids: Secondary Analysis of a Randomized Controlled Trial. Arthritis Res Ther (2014) 16(1): R13. doi: 10.1186/ar4439

88. Ally MM, Hodkinson B, Meyer PW, Musenge E, Tintinger GR, Tikly M, et al. Circulating Anti-Citrullinated Peptide Antibodies, Cytokines and Genotype as Biomarkers of Response to Disease-Modifying Antirheumatic Drug Therapy in Early Rheumatoid Arthritis. BMC Musculoskelet Disord (2015) 16:130. doi: 10.1186/s12891-015-0587-1

89. Darrah E, Giles JT, Davis RL, Naik P, Wang H, Konig MF, et al. Autoantibodies to Peptidylarginine Deiminase 2 Are Associated With Less Severe Disease in Rheumatoid Arthritis. Front Immunol (2018) 9:2696. doi: 10.3389/fimmu.2018.02696

90. Asaga H, Yamada M, Senshu T. Selective Deimination of Vimentin in Calcium Ionophore-Induced Apoptosis of Mouse Peritoneal Macrophages. Biochem Biophys Res Commun (1998) 243(3):641-6. doi: 10.1006/bbrc.1998.8148

91. Hsu PC, Liao YF, Lin CL, Lin WH, Liu GY, Hung HC. Vimentin is Involved in Peptidylarginine Deiminase 2-Induced Apoptosis of Activated Jurkat Cells. Mol Cells (2014) 37(5):426-34. doi: 10.14348/molcells.2014.2359

92. Kenny EF, Herzig A, Kruger R, Muth A, Mondal S, Thompson PR, et al. Diverse Stimuli Engage Different Neutrophil Extracellular Trap Pathways. Elife (2017) 6:e24437. doi: 10.7554/eLife.24437

93. Thiam HR, Wong SL, Qiu R, Kittisopikul M, Vahabikashi A, Goldman AE, et al. NETosis Proceeds by Cytoskeleton and Endomembrane Disassembly and PAD4-Mediated Chromatin Decondensation and Nuclear Envelope Rupture. Proc Natl Acad Sci U S A (2020) 117(13):7326-37. doi: 10.1073/pnas.1909546117

94. Martinod K, Fuchs TA, Zitomersky NL, Wong SL, Demers M, Gallant M, et al. PAD4-Deficiency Does Not Affect Bacteremia in Polymicrobial Sepsis and Ameliorates Endotoxemic Shock. Blood (2015) 125(12):1948-56. doi: 10.1182/blood-2014-07-587709

95. Cecconi M, Evans L, Levy M, Rhodes A. Sepsis and Septic Shock. Lancet (2018) 392(10141):75-87. doi: 10.1016/S0140-6736(18)30696-2

96. Colon DF, Wanderley CW, Franchin M, Silva CM, Hiroki CH, Castanheira FVS, et al. Neutrophil Extracellular Traps (NETs) Exacerbate Severity of Infant Sepsis. Crit Care (2019) 23(1):113. doi: 10.1186/s13054-019-2407-8

97. Biron BM, Chung CS, Chen Y, Wilson Z, Fallon EA, Reichner JS, et al. PAD4 Deficiency Leads to Decreased Organ Dysfunction and Improved Survival in a Dual Insult Model of Hemorrhagic Shock and Sepsis. J Immunol (2018) 200(5):1817-28. doi: 10.4049/jimmunol.1700639

98. Claushuis TAM, van der Donk LEH, Luitse AL, van Veen HA, van der Wel NN, van Vught LA, et al. Role of Peptidylarginine Deiminase 4 in Neutrophil Extracellular Trap Formation and Host Defense During Klebsiella Pneumoniae-Induced Pneumonia-Derived Sepsis. J Immunol (2018) 201 (4):1241-52. doi: 10.4049/jimmunol.1800314

99. Denning NL, Aziz M, Gurien SD, Wang P. DAMPs and NETs in Sepsis. Front Immunol (2019) 10:2536. doi: 10.3389/fimmu.2019.02536

100. Liang Y, Pan B, Alam HB, Deng Q, Wang Y, Chen E, et al. Inhibition of Peptidylarginine Deiminase Alleviates LPS-Induced Pulmonary Dysfunction and Improves Survival in a Mouse Model of Lethal Endotoxemia. Eur J Pharmacol (2018) 833:432-40. doi: 10.1016/j.ejphar.2018.07.005

101. Biron BM, Chung CS, O'Brien XM, Chen Y, Reichner JS, Ayala A. ClAmidine Prevents Histone 3 Citrullination and Neutrophil Extracellular Trap Formation, and Improves Survival in a Murine Sepsis Model. J Innate Immun (2017) 9(1):22-32. doi: 10.1159/000448808

102. Zhao T, Pan B, Alam HB, Liu B, Bronson RT, Deng Q, et al. Protective Effect of Cl-Amidine Against CLP-Induced Lethal Septic Shock in Mice. Sci Rep (2016) 6:36696. doi: 10.1038/srep36696

103. Tian Y, Qu S, Alam HB, Williams AM, Wu Z, Deng Q, et al. Peptidylarginine Deiminase 2 has Potential as Both a Biomarker and Therapeutic Target of Sepsis. JCI Insight (2020) 5(20):e138873. doi: 10.1172/jci.insight.138873

104. Yipp BG, Kubes P. NETosis: How Vital is it? Blood (2013) 122(16):2784-94. doi: 10.1182/blood-2013-04-457671
105. Deng Q, Pan B, Alam HB, Liang Y, Wu Z, Liu B, et al. Citrullinated Histone $\mathrm{H} 3$ as a Therapeutic Target for Endotoxic Shock in Mice. Front Immunol (2019) 10:2957. doi: 10.3389/fimmu.2019.02957

106. de Jong HK, Koh GC, Achouiti A, van der Meer AJ, Bulder I, Stephan F, et al. Neutrophil Extracellular Traps in the Host Defense Against Sepsis Induced by Burkholderia Pseudomallei (Melioidosis). Intensive Care Med Exp (2014) 2(1):21. doi: 10.1186/s40635-014-0021-2

107. Laukova L, Konecna B, Babickova J, Wagnerova A, Meliskova V, Vlkova B, et al. Exogenous Deoxyribonuclease has a Protective Effect in a Mouse Model of Sepsis. BioMed Pharmacother (2017) 93:8-16. doi: 10.1016/ j.biopha.2017.06.009

108. Tian Y, Russo RM, Li Y, Karmakar M, Liu B, Puskarich MA, et al. Serum Citrullinated Histone H3 Concentrations Differentiate Patients With Septic Verses non-Septic Shock and Correlate With Disease Severity. Infection (2021) 49(1):83-93. doi: 10.1007/s15010-020-01528-y

109. Singer M, Deutschman CS, Seymour CW, Shankar-Hari M, Annane D, Bauer M, et al. The Third International Consensus Definitions for Sepsis and Septic Shock (Sepsis-3). JAMA (2016) 315(8):801-10. doi: 10.1001/ jama.2016.0287

110. Rowland T, Hilliard H, Barlow G. Procalcitonin: Potential Role in Diagnosis and Management of Sepsis. Adv Clin Chem (2015) 68:71-86. doi: 10.1016/ bs.acc.2014.11.005

111. Dewyer NA, El-Sayed OM, Luke CE, Elfline M, Kittan N, Allen R, et al. Divergent Effects of Tlr9 Deletion in Experimental Late Venous Thrombosis Resolution and Vein Wall Injury. Thromb Haemost (2015) 114(5):1028-37. doi: 10.1160/TH14-12-1031

112. Guertin MJ, Zhang X, Anguish L, Kim S, Varticovski L, Lis JT, et al. Targeted H3R26 Deimination Specifically Facilitates Estrogen Receptor Binding by Modifying Nucleosome Structure. PLoS Genet (2014) 10(9):e1004613. doi: 10.1371/journal.pgen.1004613

113. Mangan MSJ, Olhava EJ, Roush WR, Seidel HM, Glick GD, Latz E. Targeting the NLRP3 Inflammasome in Inflammatory Diseases. Nat Rev Drug Discov (2018) 17(8):588-606. doi: 10.1038/nrd.2018.97

114. Li Q, Cao Y, Dang C, Han B, Han R, Ma H, et al. Inhibition of Double-Strand DNA-Sensing cGAS Ameliorates Brain Injury After Ischemic Stroke. EMBO Mol Med (2020) 12(4):e11002.

115. Khakh BS, Burnstock G. The Double Life of ATP. Sci Am (2009) 301(6):8490, 92. doi: 10.1038/scientificamerican1209-84

116. Seror C, Melki MT, Subra F, Raza SQ, Bras M, Saidi H, et al. Extracellular ATP Acts on P2Y2 Purinergic Receptors to Facilitate HIV-1 Infection. J Exp Med (2011) 208(9):1823-34. doi: 10.1084/jem.20101805

117. Basu M, Gupta P, Dutta A, Jana K, Ukil A. Increased Host ATP Efflux and its Conversion to Extracellular Adenosine is Crucial for Establishing Leishmania Infection. J Cell Sci (2020) 133(7):jcs239939. doi: 10.1242/jcs.239939

118. Gallucci S, Matzinger P. Danger Signals: SOS to the Immune System. Curr Opin Immunol (2001) 13(1):114-9. doi: 10.1016/S0952-7915(00)00191-6

119. Nolan LM, Cavaliere R, Turnbull L, Whitchurch CB. Extracellular ATP Inhibits Twitching Motility-Mediated Biofilm Expansion by Pseudomonas Aeruginosa. BMC Microbiol (2015) 15:55. doi: 10.1186/s12866-015-0392-x

120. Abbasian B, Shair A, O'Gorman DB, Pena-Diaz AM, Brennan L, Engelbrecht $\mathrm{K}$, et al. Potential Role of Extracellular ATP Released by Bacteria in Bladder Infection and Contractility. mSphere (2019) 4(5):e00439-19. doi: 10.1128/ mSphere.00439-19

121. Smolen JS, Aletaha D, McInnes IB. Rheumatoid Arthritis. Lancet (2016) 388 (10055):2023-38. doi: 10.1016/S0140-6736(16)30173-8

122. Van Steendam K, Tilleman K, Deforce D. The Relevance of Citrullinated Vimentin in the Production of Antibodies Against Citrullinated Proteins and the Pathogenesis of Rheumatoid Arthritis. Rheumatol (Oxford) (2011) 50 (5):830-7. doi: 10.1093/rheumatology/keq419

123. Jilani AA, Mackworth-Young CG. The Role of Citrullinated Protein Antibodies in Predicting Erosive Disease in Rheumatoid Arthritis: A Systematic Literature Review and Meta-Analysis. Int J Rheumatol (2015) 2015:728610. doi: 10.1155/2015/728610

124. de Vries-Bouwstra JK, Goekoop-Ruiterman YP, Verpoort KN, Schreuder GM, Ewals JA, Terwiel JP, et al. Progression of Joint Damage in Early Rheumatoid Arthritis: Association With HLA-DRB1, Rheumatoid Factor, and Anti-Citrullinated Protein Antibodies in Relation to Different Treatment Strategies. Arthritis Rheum (2008) 58(5):1293-8. doi: 10.1002/art.23439 
125. Bugatti S, Manzo A, Montecucco C, Caporali R. The Clinical Value of Autoantibodies in Rheumatoid Arthritis. Front Med (Lausanne) (2018) 5:339. doi: 10.3389/fmed.2018.00339

126. Vander Cruyssen B, Peene I, Cantaert T, Hoffman IE, De Rycke L, Veys EM, et al. Anti-Citrullinated Protein/Peptide Antibodies (ACPA) in Rheumatoid Arthritis: Specificity and Relation With Rheumatoid Factor. Autoimmun Rev (2005) 4(7):468-74. doi: 10.1016/j.autrev.2005.04.018

127. Fuchs E, Weber K. Intermediate Filaments: Structure, Dynamics, Function, and Disease. Annu Rev Biochem (1994) 63:345-82. doi: 10.1146/annurev.bi. 63.070194.002021

128. Kennedy A, Fearon U, Veale DJ, Godson C. Macrophages in Synovial Inflammation. Front Immunol (2011) 2:52. doi: 10.3389/fimmu.2011.00052

129. Davis MA, Fairgrieve MR, Den Hartigh A, Yakovenko O, Duvvuri B, Lood C, et al. Calpain Drives Pyroptotic Vimentin Cleavage, Intermediate Filament Loss, and Cell Rupture That Mediates Immunostimulation. Proc Natl Acad Sci U S A (2019) 116(11):5061-70. doi: 10.1073/pnas.1818598116

130. Holers VM. Autoimmunity to Citrullinated Proteins and the Initiation of Rheumatoid Arthritis. Curr Opin Immunol (2013) 25(6):728-35. doi: 10.1016/j.coi.2013.09.018

131. Derksen V, Huizinga TWJ, van der Woude D. The Role of Autoantibodies in the Pathophysiology of Rheumatoid Arthritis. Semin Immunopathol (2017) 39(4):437-46. doi: 10.1007/s00281-017-0627-z

132. McInnes IB, Schett G. The Pathogenesis of Rheumatoid Arthritis. N Engl J Med (2011) 365(23):2205-19. doi: 10.1056/NEJMra1004965

133. Li S, Yu Y, Yue Y, Zhang Z, Su K. Microbial Infection and Rheumatoid Arthritis. J Clin Cell Immunol (2013) 4(6):174. doi: 10.4172/2155-9899.1000174

134. Damgaard D, Senolt L, Nielsen MF, Pruijn GJ, Nielsen CH. Demonstration of Extracellular Peptidylarginine Deiminase (PAD) Activity in Synovial Fluid of Patients With Rheumatoid Arthritis Using a Novel Assay for Citrullination of Fibrinogen. Arthritis Res Ther (2014) 16(6):498. doi: 10.1186/s13075-014-0498-9

135. Damgaard D, Senolt L, Nielsen CH. Increased Levels of Peptidylarginine Deiminase 2 in Synovial Fluid From Anti-CCP-Positive Rheumatoid Arthritis Patients: Association With Disease Activity and Inflammatory Markers. Rheumatol (Oxford) (2016) 55(5):918-27. doi: 10.1093/rheumatology/kev440

136. Trombetta AC, Soldano S, Contini P, Tomatis V, Ruaro B, Paolino S, et al. A Circulating Cell Population Showing Both M1 and M2 Monocyte/ Macrophage Surface Markers Characterizes Systemic Sclerosis Patients With Lung Involvement. Respir Res (2018) 19(1):186. doi: 10.1186/s12931018-0891-z

137. Cutolo M, Trombetta AC, Soldano S. Monocyte and Macrophage Phenotypes: A Look Beyond Systemic Sclerosis. Response to: 'M1/M2 Polarisation State of M-CSF Blood-Derived Macrophages in Systemic Sclerosis' by Lescoat et al. Ann Rheum Dis (2019) 78(11):e128. doi: 10.1136/annrheumdis-2018-214371

138. Fukui S, Iwamoto N, Takatani A, Igawa T, Shimizu T, Umeda M, et al. M1 and M2 Monocytes in Rheumatoid Arthritis: A Contribution of Imbalance of M1/M2 Monocytes to Osteoclastogenesis. Front Immunol (2017) 8:1958. doi: $10.3389 /$ fimmu.2017.01958

139. Eghbalzadeh K, Georgi L, Louis T, Zhao H, Keser U, Weber C, et al. Compromised Anti-Inflammatory Action of Neutrophil Extracellular Traps in PAD4-Deficient Mice Contributes to Aggravated Acute Inflammation After Myocardial Infarction. Front Immunol (2019) 10:2313. doi: 10.3389/fimmu.2019.02313

140. Katz Sand I. Classification, Diagnosis, and Differential Diagnosis of Multiple Sclerosis. Curr Opin Neurol (2015) 28(3):193-205. doi: 10.1097/WCO. 0000000000000206

141. Oh J, Vidal-Jordana A, Montalban X. Multiple Sclerosis: Clinical Aspects. Curr Opin Neurol (2018) 31(6):752-9. doi: 10.1097/WCO. 0000000000000622

142. Wood DD, Ackerley CA, Brand B, Zhang L, Raijmakers R, Mastronardi FG, et al. Myelin Localization of Peptidylarginine Deiminases 2 and 4: Comparison of PAD2 and PAD4 Activities. Lab Invest (2008) 88(4):35464. doi: 10.1038/labinvest.3700748

143. Yang L, Tan D, Piao H. Myelin Basic Protein Citrullination in Multiple Sclerosis: A Potential Therapeutic Target for the Pathology. Neurochem Res (2016) 41(8):1845-56. doi: 10.1007/s11064-016-1920-2

144. Musse AA, Li Z, Ackerley CA, Bienzle D, Lei H, Poma R, et al. Peptidylarginine Deiminase 2 (PAD2) Overexpression in Transgenic Mice
Leads to Myelin Loss in the Central Nervous System. Dis Model Mech (2008) 1(4-5):229-40. doi: 10.1242/dmm.000729

145. Tejeda EJC, Bello AM, Wasilewski E, Koebel A, Dunn S, Kotra LP. Noncovalent Protein Arginine Deiminase (PAD) Inhibitors Are Efficacious in Animal Models of Multiple Sclerosis. J Med Chem (2017) 60(21):8876-87. doi: 10.1021/acs.jmedchem.7b01102

146. Raijmakers R, Vogelzangs J, Raats J, Panzenbeck M, Corby M, Jiang H, et al. Experimental Autoimmune Encephalomyelitis Induction in Peptidylarginine Deiminase 2 Knockout Mice. J Comp Neurol (2006) 498(2):217-26. doi: $10.1002 /$ cne. 21055

147. Falcao AM, Meijer M, Scaglione A, Rinwa P, Agirre E, Liang J, et al. PAD2Mediated Citrullination Contributes to Efficient Oligodendrocyte Differentiation and Myelination. Cell Rep (2019) 27(4):1090-102.e10. doi: 10.1016/j.celrep.2019.03.108

148. Mohanan S, Horibata S, Anguish LJ, Mukai C, Sams K, McElwee JL, et al. PAD2 Overexpression in Transgenic Mice Augments Malignancy and Tumor-Associated Inflammation in Chemically Initiated Skin Tumors. Cell Tissue Res (2017) 370(2):275-83. doi: 10.1007/s00441-017-2669-x

149. Qu Y, Olsen JR, Yuan X, Cheng PF, Levesque MP, Brokstad KA, et al. Small Molecule Promotes Beta-Catenin Citrullination and Inhibits Wnt Signaling in Cancer. Nat Chem Biol (2018) 14(1):94-101. doi: 10.1038/nchembio.2510

150. Uysal-Onganer P, MacLatchy A, Mahmoud R, Kraev I, Thompson PR, Inal JM, et al. Peptidylarginine Deiminase Isozyme-Specific PAD2, PAD3 and PAD4 Inhibitors Differentially Modulate Extracellular Vesicle Signatures and Cell Invasion in Two Glioblastoma Multiforme Cell Lines. Int J Mol Sci (2020) 21(4):1495. doi: 10.3390/ijms21041495

151. Kosgodage US, Uysal-Onganer P, MacLatchy A, Kraev I, Chatterton NP, Nicholas AP, et al. Peptidylarginine Deiminases Post-Translationally Deiminate Prohibitin and Modulate Extracellular Vesicle Release and MicroRNAs in Glioblastoma Multiforme. Int J Mol Sci (2018) 20(1):103. doi: 10.3390/ijms20010103

152. Sharma P, Lioutas A, Fernandez-Fuentes N, Quilez J, Carbonell-Caballero J, Wright RHG, et al. Arginine Citrullination at the C-Terminal Domain Controls RNA Polymerase II Transcription. Mol Cell (2019) 73(1):8496.e7. doi: 10.1016/j.molcel.2018.10.016

153. McElwee JL, Mohanan S, Horibata S, Sams KL, Anguish LJ, McLean D, et al. PAD2 Overexpression in Transgenic Mice Promotes Spontaneous Skin Neoplasia. Cancer Res (2014) 74(21):6306-17. doi: 10.1158/0008-5472.CAN14-0749

154. Li F, Miao L, Xue T, Qin H, Mondal S, Thompson PR, et al. Inhibiting PAD2 Enhances the Anti-Tumor Effect of Docetaxel in Tamoxifen-Resistant Breast Cancer Cells. J Exp Clin Cancer Res (2019) 38(1):414. doi: 10.1186/s13046019-1404-8

155. Grilz E, Mauracher LM, Posch F, Konigsbrugge O, Zochbauer-Muller S, Marosi C, et al. Citrullinated Histone H3, a Biomarker for Neutrophil Extracellular Trap Formation, Predicts the Risk of Mortality in Patients With Cancer. Br J Haematol (2019) 186(2):311-20. doi: 10.1111/bjh.15906

156. Thalin C, Lundstrom S, Seignez C, Daleskog M, Lundstrom A, Henriksson P, et al. Citrullinated Histone $\mathrm{H} 3$ as a Novel Prognostic Blood Marker in Patients With Advanced Cancer. PLoS One (2018) 13(1):e0191231. doi: 10.1371/journal.pone.0191231

Conflict of Interest: The authors declare that the research was conducted in the absence of any commercial or financial relationships that could be construed as a potential conflict of interest.

Publisher's Note: All claims expressed in this article are solely those of the authors and do not necessarily represent those of their affiliated organizations, or those of the publisher, the editors and the reviewers. Any product that may be evaluated in this article, or claim that may be made by its manufacturer, is not guaranteed or endorsed by the publisher.

Copyright (c) $2021 \mathrm{Wu}, \mathrm{Li}$, Tian, Ouyang, Ho, Alam and Li. This is an open-access article distributed under the terms of the Creative Commons Attribution License (CC BY). The use, distribution or reproduction in other forums is permitted, provided the original author(s) and the copyright owner(s) are credited and that the original publication in this journal is cited, in accordance with accepted academic practice. No use, distribution or reproduction is permitted which does not comply with these terms. 